\title{
Structural and functional characteristics of two novel members of pathogensis-related multigene family of class 10 from yellow lupine ${ }^{\not k}$
}

\author{
Luiza Handschuh, Iwona Femiak, Alina Kasperska, Marek Figlerowicz \\ and Michał M. Sikorski ${ }^{\bowtie}$ \\ Institute of Bioorganic Chemistry, Polish Academy of Sciences, Poznań, Poland
}

Received: 06 July, 2007; revised: 26 November, 2007; accepted: 04 December, 2007 available on-line: 13 December, 2007

\begin{abstract}
PR-10 proteins (pathogensis-related), ubiquitous within the plant kingdom, are usually encoded by multigene families. To date we have identified 10 homologous $p r-10$ genes in a yellow lupine cDNA library. Here, the structure and expression of two newly identified yellow lupine pr-10 genes (LlYpr10-2b and LlYpr10-2f) are presented. Many potential regulatory sites were found in both gene promoters including common ones as well as those unique for each gene. However, promoter deletion analysis in transgenic tobacco plants revealed similar patterns of reporter gene (gus) expression. Shortened fragments of both gene promoters studied caused high GUS activity in leaves (along vascular bundles), stamen stigma, anthers and pollen grains. When conjugated with longer LlYpr-10.2 promoter fragments, GUS was additionally present in petal edges. Only a long fragment of the LlYpr10-2b gene promoter caused GUS expression in the stem. In yellow lupine the $p r-10.2$ genes are present in all studied organs, but their level of expression depends on the stage of development and is affected by wounding, oxidative stress and salicylic acid treatment. Silencing of the $L l p r-10.2 b$ gene in 4-week-old yellow lupine plants did not lead to any visible symptoms, which suggests that the function of the silenced gene is supplemented by its close homologues, still present in the studied plants.
\end{abstract}

Keywords: pathogensis-related genes and proteins, yellow lupine, promoter analysis, salicylic acid, hydrogene peroxide, gene silencing

\section{INTRODUCTION}

Many eukaryotic proteins, including actins, hemoglobins, immunoglobulins, tubulins, interferons, histones or MAP kinases, are encoded by multigene families (Mishra et al., 2006; Silverstein et al., 2006; Schenk et al., 2006). The coexistence of related genes in one organism presumably results from duplications and modifications of ancestral genes or whole genomes. Multigene families are particularly widespread in higher plants, which are often polyploid organisms possessing huge genomes (Schenk et al., 2006).
An example of the numerous plant gene families is one encoding class 10 of pathogensis-related proteins (PR-10). It often contains at least 10 homologous genes per species and, consequently, the same or a higher number of protein isoforms can be synthesized in plant cells (van Loom \& van Strien, 1999; Liu \& Ekramoddoullah, 2004; Beuning et al., 2004; Schenk et al., 2006). Despite their ubiquity within the plant kingdom, the function of PR-10 proteins remains unclear. The first $p r-10$ gene was identified in parsley cell culture subjected to fungal elicitor treatment (Somssich et al., 1986; 1988). During the last 30

${ }^{\square}$ Corresponding author: Michal M. Sikorski, Institute of Biorganic Chemistry, Polish Academy of Sciences, Z. Noskowskiego 12/14, 61-704 Poznan, Poland; tel.: (48) 618528503 ext. 108; fax: (48) 61852 0532; e-mail: mmsik@ibch.poznan.pl Supplementary materials available at: www.actabp.pl

Abbreviations: auxRE, auxin-response element; Bet v 1, Betula verrucosa protein 1; Cdx, caudal type, homeobox transcription factor; Dof proteins, DNA-binding with One Finger proteins; dpi, days post infection/infiltration; GRE, glucocorticoid-response element; GUS, $\beta$-glucuronidase; HSF, heat-shock factor; Hyp 1, Hypericum perforatum protein 1; Llcsbp, Lupinus luteus cytokinin-specific binding protein; Llpr-10, Lupinus luteus pathogenesis-related class 10 gene/protein; MAP, mitogen-activated protein kinase; MtN13, Medicago truncatula nodulin gene; PR, pathogenesis-related; SA, salicylic acid; SAR, systemic acquired resistance; WRKY, transcription factor family with WRKY domain. 
years many reports on pathogensis and stress-related expression of $p r-10$ genes in different plant species have been published (Crowell et al., 1992; Pinto \& Ricardo, 1995; Pozueta-Romero et al., 1995; Swoboda et al., 1996; Walter et al., 1996; Hoffmann-Sommergruber et al., 1997; Wang et al., 1999; McGee et al., 2001; Liu \& Ekramoddoullah, 2004; Beuning et al., 2004; Finkler et al., 2005). In addition, papers demonstrating constitutive expression of $p r-10$ genes appeared, suggesting a more general biological role of PR-10 proteins in plant developmental program (Pozueta-Romero et al., 1995; Vanek-Krebitz et al., 1995; Balsamo et al., 1995; Swoboda et al., 1996; Huang et al., 1997; Strömvik et al., 1999; Sikorski et al., 1999; Liu \& Ekramoddoullah, 2003; Beuning et al., 2004; Finkler et al., 2005). Also, tissue-specific expression of pr-10 genes, e.g. in roots (Sikorski et al., 1999; Liu \& Ekramoddoullah, 2003), flowers (Pozueta-Romero et al., 1995), pods (Strömvik et al., 1999), fruits (VanekKrebitz et al., 1995), tapetum (Huang et al., 1997) or pollen grains (Swoboda et al., 1996) was documented. Many of the PR-10 class members were recognized as major food and pollen allergens. The best known pollen-associated allergens are PR-10 proteins encoded by birch genomes with Bet $\mathrm{v} 1$ as a classic example (Schenk et al., 2006). Some of the PR10 proteins display weak ribonuclease activity (Moiseyev et al., 1994; 1997; Swoboda et al., 1996; Bufe et al., 1996; Bantignies et al., 2000; Zhou et al., 2002; Wu et al., 2003; Park et al., 2004, Chadha et al., 2006), but it is still difficult to estimate the contribution of this nucleolytic activity to their real function. PR-10 proteins also share homology with (S)-norcoclaurine synthase (NCS), an enzyme implicated in biosynthesis of benzylisoquinoline alkaloids, but recombinant PR-10 polypeptides do not show a similar enzymatic activity (Liscombe et al., 2005). Another enzymatic activity has been recently demonstrated for Hyp 1, a PR-10 protein extracted from St. John's wort (Hypericum perforatum), responsible for biosynthesis of hypericin from emodin (Bais et al., 2003). The gene coding for Hyp 1 protein shows $45.1 \%$ identity to Bet $\mathrm{v} 1$ class allergens.

In legumes, PR-10 proteins can be additionally considered in a symbiosis context. We discovered the first two yellow lupine (Lupinus luteus) PR-10 proteins (LIPR-10) in root extracts, as a result of differential expression analysis during symbiotic interaction with soil bacteria Bradyrhizobium sp. (Lupinus) (Sikorski, 1997; Sikorski et al., 1999). Both proteins, consisting of 156 amino-acid residues, are highly expressed in root tissues except for mature root nodules (Sikorski et al., 1999). This pattern of expression in roots is typical for all known legume PR-10 proteins except one - alfalfa MtN13 (Medicago truncatula nodulin gene), which is highly expressed exclusively in the nodule cortex (Gamas et al., 1998).
Yellow lupine protein LIPR-10.1B is constitutively expressed in all aerial parts of plants whereas its close homologue, LIPR-10.1A, was detected only in stem and leaves of plants infected with the pathogen Pseudomonas syringae (Sikorski, unpublished).

Inspired with the idea of PR-10 proteins significance in the symbiotic interaction, we searched for a yellow lupine homologue of the nodule-specific $M t N 13$. As a result of the screening of a yellow lupine cDNA library with MtN13 coding sequence as a probe, six new yellow lupine $p r-10$ homologues were identified (Sikorski et al., 2000; Handschuh et al., 2004).

Summarizing, the yellow lupine $p r-10$ gene family encompassed to date 10 homologues, including two genes encoding cytokinin-specific binding proteins $(c s b p)$, classified together with $p r-10$ due to their similar tertiary structure (Pasternak et al., 2006) (Supplementary Table 1). Three subclasses of PR-10 proteins (LIPR-10.1, LIPR-10.2 and LICSBP) were distinguished in yellow lupine, according to the level of predicted amino-acid sequence identity. The highest identity values at the nucleotide level were noticed within the subclass Llpr-10.2, where two pairs of very close homologues were identified: Llpr-10.2al Llpr-10.2d and Llpr-10.2b/Llpr-10.2c (Supplementary Table 2).

Here, we present two new yellow lupine $p r$ 10 genes, which were identified in a yellow lupine genomic library and were classified as members of subclass Llpr-10.2: LlYpr-10.2.b and LlYpr-10.2.f. Their promoter activities were studied in transgenic tobacco. Expression of three Llpr-10.2 genes (LlYpr-10.2.a, LlYpr-10.2.b and LlYpr-10.2.e) was also monitored in yellow lupine leaves during development, in wounded leaves and leaves infected with the pathogenic bacterium $P$. syringae. The expression profiles of five Llpr-10 genes belonging to two $p r-10$ subclasses were determined in roots and leaves of yellow lupine plants treated with hydrogen peroxide and salicylic acid. In addition, the effect of Llpr$10.2 b$ gene silencing in yellow lupine plants was investigated.

\section{MATERIALS AND METHODS}

Screening of a yellow lupine genomic library. A genomic library of yellow lupine (made in $\lambda$-phage vector EMBL-3 by Clontech, USA) was screened according to the manufacturer's recommendations. Hybridization was performed overnight at $65^{\circ} \mathrm{C}$ using ${ }^{32} \mathrm{P}$-labeled full coding sequence of $L l p r-10.2 b$ gene as a probe. The membranes were subsequently washed: first in $2 \times$ SSC at room temperature, then in $1 \times \mathrm{SSC}$ at $60^{\circ} \mathrm{C}$ and in $0.1 \times \mathrm{SSC}$ at $60^{\circ} \mathrm{C}$. After a 3-day-exposure of filters at $-70^{\circ} \mathrm{C}, \mathrm{X}$ - 
ray films were developed and hybridizing colonies were collected.

Cloning of LlYpr-10.2 genes. A $5 \mathrm{~kb}$ fragment of the LlYpr-10.2.b gene containing entire coding sequence, 5' UTR and promoter, was PCR-amplified and cloned into pDrive Cloning Vector (Promega). LlYpr-10.2f gene, containing coding sequence and $1357 \mathrm{bp}$ upstream from the start codon was cloned into pBS-SK plasmid. The prepared plasmids were used for DNA sequencing and construction of binary vectors for promoter deletion analysis.

In silico promoter analysis. Potential transcription factor-binding sites and regulatory motifs were searched for in the following promoter regions of the LlYpr-10.2 genes: 1425 bases upstream from the start codon in the case of LlYpr-10.2b and 1353 bases upstream from the start codon in the case of LlYpr-10.2f, using web-available software: TRANSFAC (Heinemeyer et al., 1998; http://www.cbrc.jp/research/db/TFSEARCH.html), TFSEARCH (Akiyama et al., 1998; http://www.rwcp.or.jp/papia/) and TESS (Schug, 2003; http://www.cbil.upenn.edu/cgi-bin/tess/ tess). Some additional regulatory motifs not available in the above softwares but present in other plant and $p r-10$ gene promoters were also identified in the Llpr-10.2 gene promoters studied here.

Promoter deletion analysis. Two promoter deletion fragments per gene were PCR amplified, digested and cloned to the binary vector pPR97 (kindly provided by Dr. Pascal Gamas from the Institut des Plantes Vegetales, Gif sur Ivette, France) upstream the coding sequence of $\beta$-glucuronidase (GUS). Then, the vectors were used for transformation of Agrobacterium tumefaciens with the three parental mating and electroporation methods. The bacteria carrying the plasmids were subsequently introduced to Nicotiana tabacum, cv. Wisconsin 38. Every transformation event gave 40-70 transgenic plants. Genomic DNA was isolated from over 130 plants and used as a template for PCR with universal primers, designed for the insert-flanking sequences of pPR97 plasmid. From the PCR-positive plants single organs were taken and incubated $\left(24 \mathrm{~h}, 37^{\circ} \mathrm{C}\right)$ with GUS substrates (Jefferson et al., 1987).

Transgenic plant regeneration. Leaves of Nicotiana tabacum, cv. Wisconsin 38, grown in vitro, were cut into small pieces $\left(0.5-1 \mathrm{~cm}^{2}\right)$ and incubated for $5 \mathrm{~min}$ in the YEB medium containing transformed A. tumefaciens cells $\left(\mathrm{OD}_{600} 0.8-1\right)$. Then, the leaf segments were kept for 3 days in dark on MS permanent medium. Passaged to MS-T medium with antibiotics (kanamycin and carbenicillin), plants regenerated at $24^{\circ} \mathrm{C}, 16 \mathrm{~h}$ photoperiod. Single plants were cultivated on MS medium with selective antibiotics until the roots developed (Trinh et al., 2001).

Plant genomic DNA isolation. The harvested plant tissues were immediately frozen in liquid ni- trogen and ground using mortar and pestle. Gently shaken in buffer containing $1 \% \mathrm{CTAB}$, the plant powder was incubated for $1 \mathrm{~h}$ at $65^{\circ} \mathrm{C}$. Afterwards, DNA was extracted with equal volume of chloroform/isoamyl alcohol $(24: 1, \mathrm{v} / \mathrm{v})$ and precipitated overnight with isopropanol ( 0.7 volume) at $-20^{\circ} \mathrm{C}$. Following centrifugation (30 $\mathrm{min}, 13200 \mathrm{rpm}, 4^{\circ} \mathrm{C}$ ) DNA pellet was dissolved in $0.5 \times \mathrm{TE}$ buffer.

Growth of yellow lupine plants. Yellow lupine plants were cultivated in a sterile growth chamber at $23^{\circ} \mathrm{C}$ with a $16 \mathrm{~h}$ day and $8 \mathrm{~h}$ night photoperiod. Symbiosis was induced by inoculation of 3-day-old seedlings with soil bacteria (Bradyrhizobium sp. Lupinus). Leaves of 4-week-old plants were mechanically wounded (using sterile glasspaper) or infiltrated (into bottom part of the leaf using syringe without needle) with the pathogenic bacterium Pseudomonas syringae pv. pisi grown in YDA medium at $30^{\circ} \mathrm{C}$ to $\mathrm{OD}_{600}=1.0$ (according to Breda et al., 1996). Control plants were infiltrated with $10 \mathrm{mM} \mathrm{MgCl}_{2}$. Two other sets of 4-week-old plants were watered with $100 \mu \mathrm{M}$ salicylic acid (SA) solution and $10 \mathrm{mM}$ hydrogen peroxide $\left(\mathrm{H}_{2} \mathrm{O}_{2}\right)$ solution, respectively. Leaves were harvested directly before induction and $3,6,9,24$ and $48 \mathrm{~h}$ after treatment, frozen in liquid nitrogen and ground using mortar and pestle. Total RNA and proteins were extracted from the same tissue samples.

Gene silencing. The full coding sequence of the $L l p r-10.2 b$ gene was cloned into the binary expression vector pAWo59 in sense $\left(\mathbf{2} \mathbf{b}_{\mathrm{SE}}\right)$, antisense $\left(2 \mathbf{b}_{\mathrm{AS}}\right)$ or both orientations simultaneously, divided by a shortened intron of the chalcone synthase gene in order to produce a transcript adopting a long hairpin structure $\left(\mathbf{2 b}_{\mathrm{HP}^{\prime}}\right.$, Fig. $\left.5 \mathrm{~A}\right)$. Each construct was introduced into Agrobacteria and agroinfiltrated into 4-week-old yellow lupine plants. A. tumefaciens cells were transformed with the plasmids using electroporation and three parental mating methods. The transformed Agrobacteria were then grown in liquid YEB medium with kanamycin and rifampicin to $\mathrm{OD}_{600}$ 0.5-0.8. Pelleted bacteria were suspended in $10 \mathrm{mM} \mathrm{MgCl}{ }_{2}$ and infiltrated with a syringe to leaf blades of 4-week-old yellow lupine plants in a sterile growth chamber. Leaves were collected 5, 11, 22, 33 and 57 days after infiltration and treated as after gene expression induction described above.

Plant RNA isolation and RT-PCR analysis. RNA was isolated with RNeasy Plant Mini Kit (Qiagen) and DNase I digested. RT-PCR reaction was performed with One-Step RT-PCR Kit (Qiagen) using specific primers complementary to the $3^{\prime}$ and $5^{\prime}$ untranslated regions of the Llpr-10.1a, Llpr-10.1b, Llpr-10.2a, Llpr-10.2b and Llpr-10.2e cDNA clones.

Western blot analysis. Ground tissues were shaken in $20 \mathrm{mM}$ Tris/HCl buffer ( $\mathrm{pH} 7.5) / 5 \%$ glycerol/10 mM $\beta$-mercaptoethanol and kept on ice for 0.5 
h. The extracts were then centrifuged (14 $000 \mathrm{rpm}, 30$ $\min , 4^{\circ} \mathrm{C}$ ), and the supernatants containing total soluble protein fraction were collected. The proteins (1 $\mu \mathrm{g}$ per well) were separated in $17 \%$ polyacrylamide/ SDS gel in $1 \times$ Laemmli buffer. After electrophoresis, the proteins were blotted to a PVDF membrane with a semi-dry method, using a Trans-Blot SD Semi Dry Transfer Cell (Biorad). The membranes were subsequently blocked $1 \mathrm{~h}$ in $1 \times \mathrm{PBS} / 5 \%$ fat-free milk and incubated overnight with a polyclonal rabbit serum anti-LlPR-10.2Bs (Handschuh et al., 2004; Figs. 3 and 4) diluted $1: 3000$ in $1 \times \mathrm{PBS} / 5 \%$ fat-free milk/ $/ 0.05 \%$ Tween 20 or with polyclonal rabbit serum anti-LIPR10.1A (Sikorski et al., 1999; Fig. 3) diluted 1:10 000. Next, the blots were incubated first with goat antirabbit biotinylated antibodies (Amersham), and then with streptavidin-CIP; thoroughly washed in $1 \times$ PBS, $1 \times$ PBS/Tween 20 and again $1 \times$ PBS. The immune reaction was finally detected after short incubation with CIP substrates (BCIP and NBT, Sigma).

\section{RESULTS}

\section{Identification of new pr-10 genes in yellow lupine genome}

In order to identify new genes encoding yellow lupine LIPR-10.2 proteins, we have screened a genomic library of yellow lupine with the Llpr-10.2b coding sequence as a probe. At high stringency conditions, we were able to find only two genomic sequences - one exactly overlapped the probe sequence (referred as $L l Y p r-10.2 b$ ), while the other was most similar but not identical with Llpr-10.2e. This gene was identified as a new $p r-10$ lupine homologue and, consequently, named LlYpr-10.2f. The structure of $L l Y p r-10$ genes is schematically presented in Fig. 1. A TATA box sequence, TATAAATA, is localized in LlYpr-10.2b between 84 and $76 \mathrm{bp}$ and in LlYpr-10.2f between 80 and $72 \mathrm{bp}$ upstream of the ATG start codon. The conserved polyadenylation signal, AATAA, was identified in 3' UTRs. Both genes contain a single intron of similar length (330 and 314 bp), placed in a conserved position - after the first base of the triplet encoding glycine 61 (Table 1). In contrast to the high degree of identity at the cDNA level $(79 \%)$ and within the intron sequences $(73 \%)$, the similarity within promoter sequences of $L l Y p r-$ $10.2 b$ and $L l Y p r-10.2 f$ is significantly lower (49\%).

Screening of the genomic library for other LlYpr-10.2 gene sequences was not successful. Nevertheless, the LlYpr-10.2a intron sequence was identified as a result of PCR involving yellow lupine genomic DNA as a template and Llpr-10.2a-specific starters designed to be used in RT-PCR analysis. The obtained product was by about $200 \mathrm{bp}$ longer than the corresponding RT-PCR product (not shown). Sequencing of the PCR product revealed the entire Llpr-10.2a coding sequence interrupted in the conserved position (as indicated above) by a 242 bp-long intron, sharing $54 \%$ and $55 \%$ identity with the intron sequences of LlYpr-10.2b and LlYpr-10.2f genes, respectively. All three introns have the same boundary sequences: TTGAGG/GTTAGTA...AG/ GTGG. Table 1 summarizes basic information concerning all $p r-10$ genes that were identified in yellow lupine genomic library, including two genes representing Llpr-10.1 subclass described earlier (Sikorski et al., 1998).

\section{Screening for regulatory elements in yellow lupine} LlYpr-10.2 gene promoter

Analysis of the LlYpr-10.2b and LlYpr-10.2f promoter sequences in silico led to the identification of many potential regulatory elements (72 and 98, respectively) (Supplementary Table 3). More than half of them appear in both promoters, but with different frequency and orientation.

The most conservative regions of the LlYpr$10.2 \mathrm{~b}$ and LlYpr-10.2f promoters are located within approx. $230 \mathrm{bp}$ upstream of the start codon. Here, the basic signals determining transcription initiation are located. A conserved TATA box (TATAAATA), recognized by various transcription factors, is found

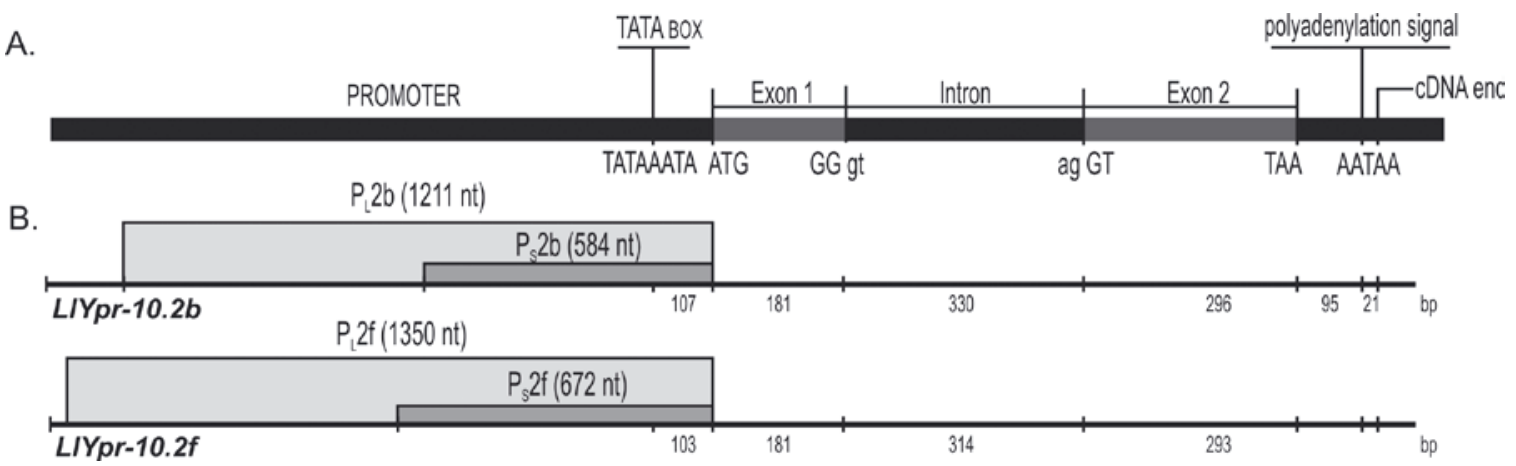

Figure 1. General scheme of the yellow lupine LlYpr-10 gene structure (A) and two genes used in promoter deletion analysis (B).

Promoter fragments are indicated. 
Table 1. Intron length and localization in LlYpr-10 genes.

Introns are located after the first letter of the triplet coding for the 61st amino acid.

\begin{tabular}{lccc}
\hline Gene name & Intron position & Intron length (bp) & GenBank Acc. No. \\
\hline LlYpr-10.1a & 61 (Asp) & 457 & AF002277 \\
LlYpr-10.1b & 61 (Gly) & 797 & AF002278 \\
LlYpr-10.2a & 61 (Gly) & 242 & AY729802 \\
LlYpr-10.2b & 61 (Gly) & 330 & AY377535 \\
LlYpr-10.2f & 61 (Gly) & 314 & AY303549 \\
\hline
\end{tabular}

in the same position in both promoters, flanked by identical 5-nt-long sequences. The CAAT sequence frequent in both promoters probably plays a role of the CAAT box, implicated in transcription initiation, only in the LlYpr-10.2b promoter, where it is proximal to the TATA box. Within the most conservative regions of both promoters one site recognized by NIT2, activator of nitrogen-regulated genes, one gibberellin-response element and a few AT-com traits, specific for heat-shock protein coding genes were found. However, some significant differences appear in this region as well. For instance, only the LlYpr$10.2 f$ gene possesses, in proximity of the TATA box, a motif similar to the GC box (GGGCGG), present in many constitutively expressed genes. The same LlYpr-10.2f promoter fragment (236 bp upstream of the start codon) contains one PBF (prolamine binding factor) site, present in maize, wheat and barley gene promoters and recognized by a family of single zinc finger plant transcription factors, Dof proteins (DNA-binding with One Finger). One P motif, implicated in the flavonoid biosynthesis pathway, one E-box (hexanucleotide sequence CAAATG; binding site of many nuclear factors) and one AT-rich Ford consensus sequence, specific for late nodulin genes, are also located in this region of $L l Y p r-10.2 f$ promoter. Within the corresponding region of LlYpr-10.2b promoter (232 bp upstream of the start codon) there is one motif recognized by Dof2 transcription factor, two TCA-like sequences, implicated in response to salicylic acid, two sites recognized by chicken CdxA homeobox gene (caudal type homeobox transcription factor, $\mathrm{Cdx}-1)$ and two heat-shock factor (HSF) sites described in Drosophila. More sites recognized by Dof proteins are located upstream of the most conservative regions and except for the common AAAG core, have different sequences in both LlYpr10.2 promoters. Additionally, the LlYpr-10.2b promoter contains three direct repeats of a characteristic sequence (TCATGNA) of unknown function.

\section{Deletion analysis of $L l Y p r-10.2$ promoters}

In order to complement the in silico analysis, LlYpr-10.2 promoter deletion analysis was performed in transgenic tobacco. Four putative promoter fragments upstream of the start codon were amplified: short $\mathbf{P}_{\mathrm{S}} \mathbf{2 b}(584 \mathrm{bp})$ and long $\mathbf{P}_{\mathrm{L}} \mathbf{2 b}(1211 \mathrm{bp})$ representing the LlYpr-10.2b gene, as well as short $\mathbf{P}_{\mathrm{S}} \mathbf{2 f}$ (672 bp) and long $\mathbf{P}_{\mathbf{L}} \mathbf{2 f}(1350 \mathrm{bp}$ ) representing LlYpr$10.2 f$ (Fig. 1). Each fragment was fused to the coding sequence of $\beta$-glucuronidase gene and introduced into the model plant Nicotiana tabacum. Promoter activity was then analyzed in different plant organs. Generally, we observed similar, ubiquitous GUS expression in plants transformed with either of the four constructs $\left(\mathbf{P}_{\mathrm{S}} \mathbf{2 b}, \mathbf{P}_{\mathrm{L}} \mathbf{2 b}, \mathbf{P}_{\mathrm{S}} \mathbf{2 f}\right.$ and $\left.\mathbf{P}_{\mathrm{L}} \mathbf{2 f}\right)$ (Fig. 2). A definitely uniform, high expression pattern was noticed in stamens - limited to stigma, and leaves - associated with vascular bundles, which was clearly visible in light microscope pictures. Although the GUS expression pattern in anthers was not uniform, pollen grains clearly showed strong GUS activity in plants transformed with either of the four constructs. An evident discrepancy was found in stems where GUS was expressed exclusively in the case of the $\mathbf{P}_{\mathbf{L}} \mathbf{2 b}$ construct, harboring the longer part of the LlYpr-10.2b gene promoter. Additionally, neither of the short promoter fragments $\left(\mathbf{P}_{\mathrm{s}} \mathbf{2 b}\right.$ and $\left.\mathbf{P}_{\mathrm{s}} \mathbf{2 f}\right)$ was sufficient to ensure $\beta$-glucuronidase expression in tobacco petals. The longer promoter fragments $\left(\mathbf{P}_{\mathbf{L}} \mathbf{2 b}\right.$ or $\mathbf{P}_{\mathrm{L}} \mathbf{2 f}$ ) caused GUS accumulation but limited to the edges of petals. The most diverse expression of the reporter gene was observed in the ovary, encompassing the whole organ in the case of the $\mathbf{P}_{\mathbf{L}} 2 \mathbf{f}$ construct, but concentrating in the bottom and the edges in the case of the $\mathbf{P}_{\mathrm{L}} \mathbf{2 b}$ and $\mathbf{P}_{\mathrm{S}} \mathbf{2 f}$ constructs. In the case of the $\mathbf{P}_{\mathrm{S}} \mathbf{2 b}$ construct, containing the short LlYpr-10.2b promoter fragment, the activity of the reporter gene was undetectable in the ovary.

\section{Llpr-10 gene expression pattern in leaves. Response to wounding, pathogen, salicylic acid and hydrogen peroxide}

Independently of the promoter deletion analysis in transgenic tobacco we followed Llpr-10 gene expression in the native system - yellow lupine plants, cultivated in a sterile growth chamber (Fig. 3). Results presented in Fig. 3A - semiquantitative RT-PCR - show the expression levels of three Llpr-10.2 subclass members in yellow lupine leaves during development. In order to detect the Llpr-10.2a transcript, six times more template and 
P1: L/Ypr-10.2b promoter (584 bp)

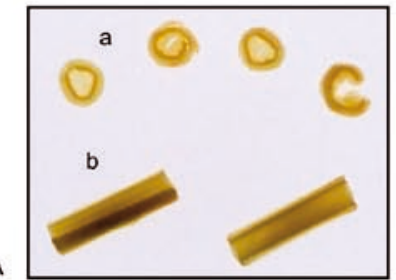

B

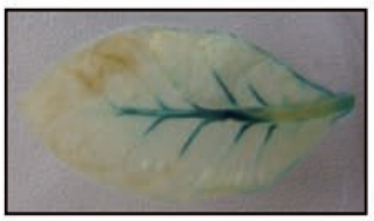

C

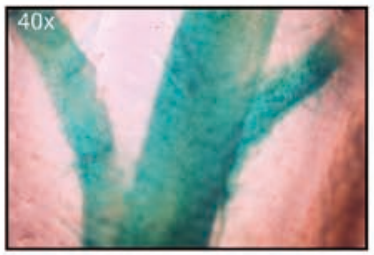

D

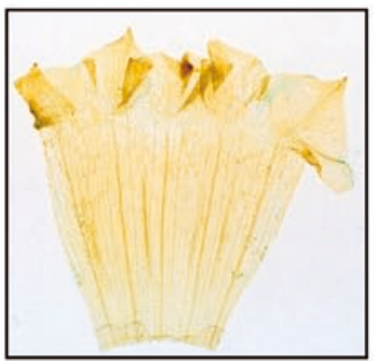

E

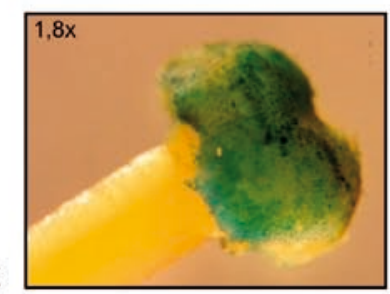

F

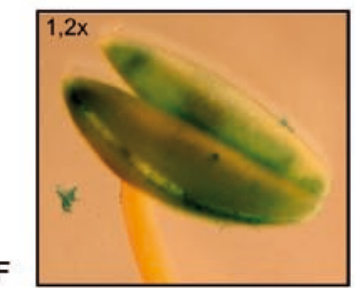

G

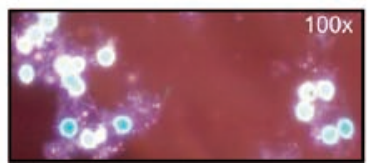

P3: L/Ypr-10.2f promoter (672 bp)
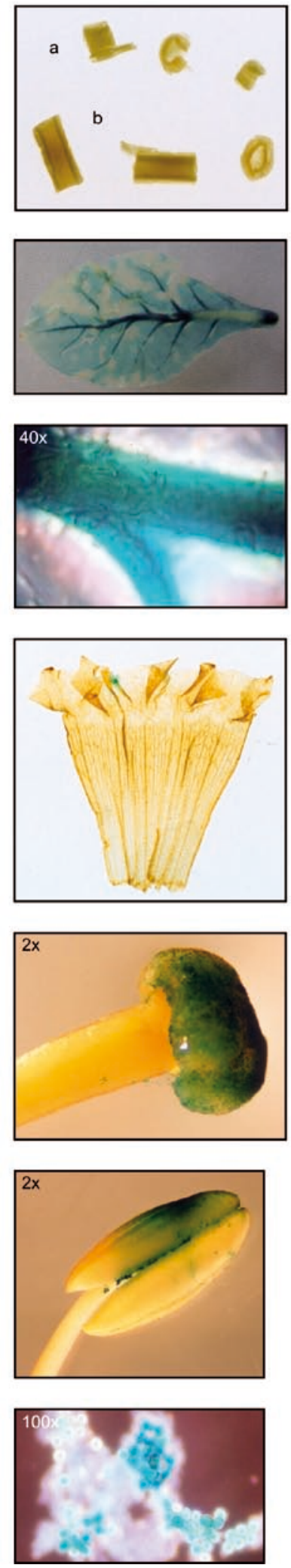

P2: L/Ypr-10.2b promoter (1211 bp)

P4: L/Ypr-10.2f promoter (1350 bp)
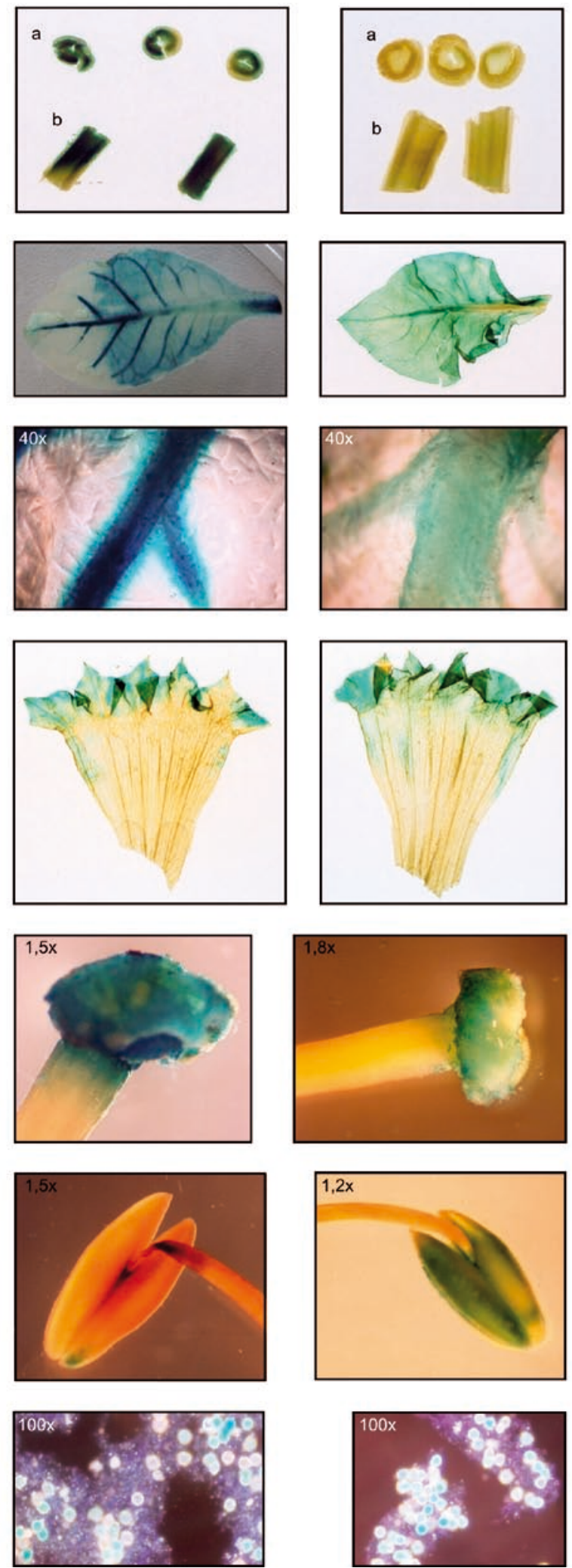
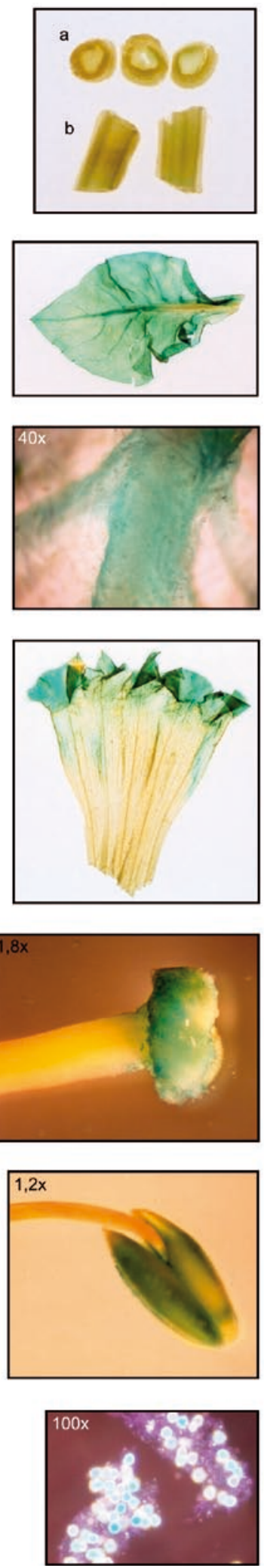

Figure 2. In situ histochemical localization of GUS activity in transgenic tobacco plants expressing LlYpr-10:GUS fusion under the control of different promoter regions of yellow lupine $p r-10$ genes: $L l Y p r-10.2 b$ and $L l Y p r-10.2 f$.

(A) stem: a. cross section, b. longitudinal section; (B) leaf; (C) magnified leaf (vascular bundles); (D) flower petals; (E) ovary; (F) stamen stigma; $(\mathrm{G})$ anther; $(\mathrm{H})$ pollen grains. 

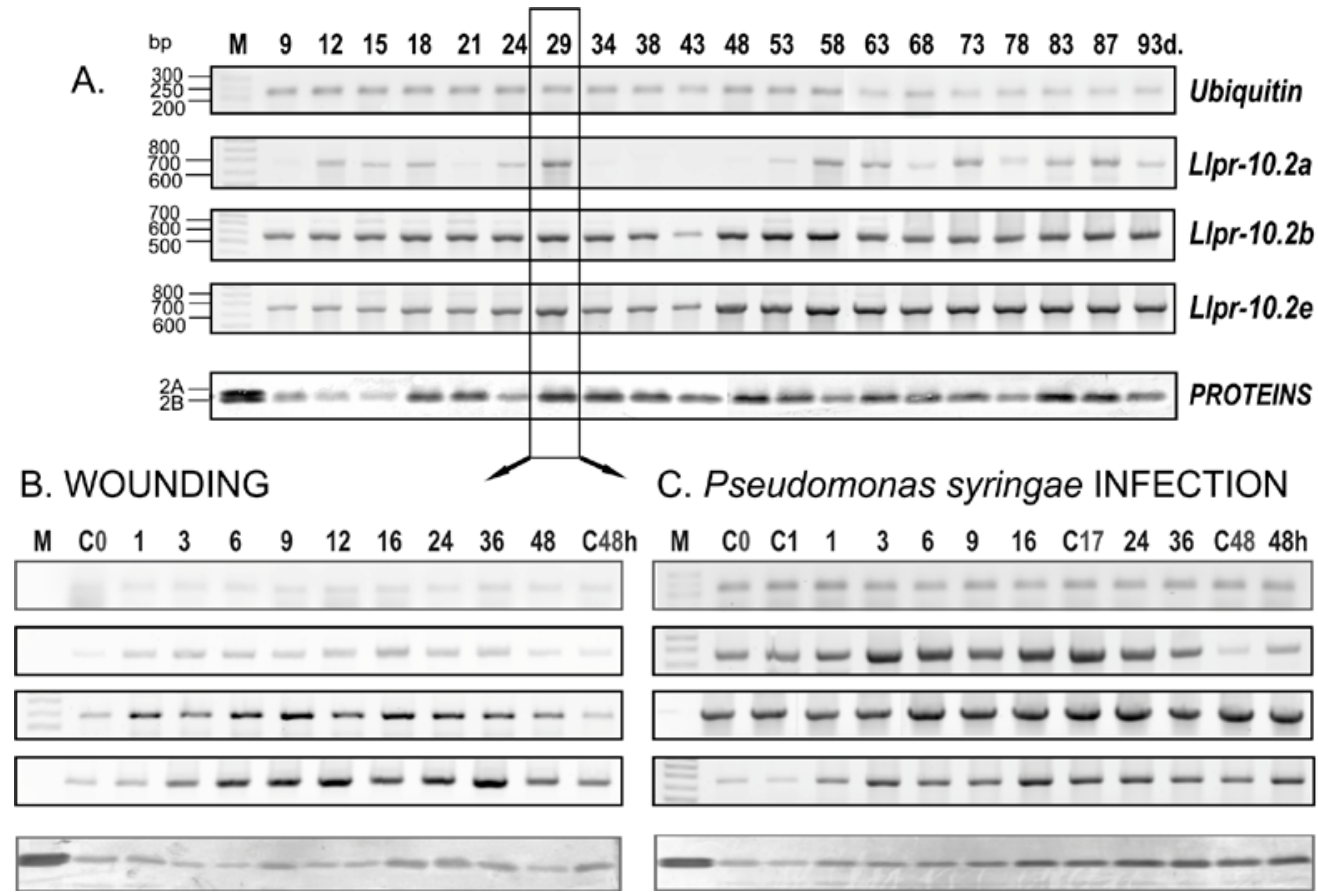

$\begin{array}{llllllllllllll}M & \text { C0 } & \text { C1 } & 1 & 3 & 6 & 9 & 16 & \mathrm{C} 17 & 24 & 36 & \mathrm{C} 48 & 48 \mathrm{~h}\end{array}$

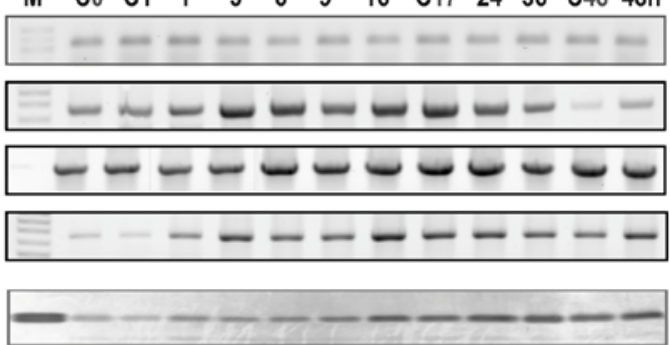

Ubiquitin

Llpr-10.2a

Llpr-10.2b

Llpr-10.2e

Figure 3. Expression pattern of genes representing Llpr-10.2 subclass in yellow lupine leaves.

(A) leaves during development, (B) wounded leaves, (C) leaves infected with Pseudomonas syringae. Total RNA template concentration and PCR cycle number were as follows: with primers for ubiquitin $0.2 \mu \mathrm{g} / 35 \mathrm{cycles}$; for Llpr-10.2a $0.6 \mu \mathrm{g} / 40$ cycles; for Llpr-10.2b and Llpr-10.2e $0.1 \mu \mathrm{g} / 30$ cycles. RT-PCR product sizes were as follows: Llpr-10.2b - 583 bp; Llpr$10.2 e-666 \mathrm{bp}$; ubiquitin - $230 \mathrm{bp}$. Protein accumulation was analyzed using Western blot performed after SDS/PAGE of $1 \mu \mathrm{g}$ total protein extract per well and antibodies anti-L1PR-10.2 subclass. M - molecular weight markers; C0, C1, C17, C48 - leaves of control plants $0,1,17$ and $48 \mathrm{~h}$ after treatment, respectively; B - wounded; C - infiltrated with 10 $\mathrm{mM} \mathrm{MgCl}$.

more PCR cycles were needed than in the case of the Llpr-10.2b and Llpr-10.2e transcripts. This difference in the expression level confirms our earlier, preliminary results (Handschuh et al., 2004). In addition, there were time points where the Llpr-10.2a transcript was undetectable $(9,21$ and 34-48-day-old plants). In contrast, Llpr-10.2b and Llpr-10.2e genes reveal similar, constitutive expression profiles. The only difference is that $L l p r-10.2 b$ gene expression is more uniform, while Llpr-10.2e transcript undergoes slight changes during plant development. In young leaves the amount of Llpr-10.2e transcript is clearly smaller than in ageing ones. The same tendency can be observed for the level of protein subclass LIPR10.2 .

Taking into account the fact that in 29-day-old plants all Llpr-10.2 genes studied were expressed, we decided to check their response to wounding and selected exogenous elicitors in 4-week-old yellow lupine plants. First, leaves of one group of plants were mechanically wounded (Fig. 3B) while the second group was infiltrated with pathogenic bacteria Pseudomonas syringae pv. pisi (Fig. 3C). Comparing to ubiquitin, expression of all $p r-10$ genes studied was elevated in both plant groups: Llpr-10.2a between 3$36 \mathrm{~h}, \mathrm{Llpr}-10.2 \mathrm{~b}$ and Llpr-10.2e between 1-48 h, which was reflected also in a gradual protein increase
(Fig. 3B and C). However, as shown in panel C, control leaves (C17), infiltrated with buffer only instead of the pathogenic bacteria suspension, reveal the same level of increase independently of the studied gene. This evidently proves that the observed elevated expression of Llpr-10.2 genes is a consequence of mechanical wounding, not pathogen infection per se. Thus, the following experiment was based on another approach - two elicitors - hydrogen peroxide, involved in the oxidative stress (Ślesak et al., 2007) and salicylic acid, one of the crucial signaling molecule in plant defense response (Shah, 2003), were supplied as water solutions into the soil, not directly into leaves. Then, expression of Llpr-10 genes was determined in roots as well as in leaves within $48 \mathrm{~h}$ after treatment (Fig. 4). The effect of hydrogen peroxide was definitely weaker than that caused by salicylic acid. Only in roots treated with hydrogen peroxide solution, the expression of two genes slightly increased - Llpr-10.1a, representing yellow lupine subclass Llpr-10.1, and Llpr-10.2a, representing subclass Llpr-10.2. Quite the opposite, in the same tissues the expression level of Llpr-10.2b and Llpr-10.2e gradually diminished, while the Llpr-10.1b gene in roots and all the studied genes in leaves seemed not to be sensitive to hydrogen peroxide. Salicylic acid (SA) caused changes in the expression level all 
ROOTS

LEAVES

\begin{tabular}{|c|c|c|c|c|c|c|c|c|c|c|c|c|c|}
\hline \multirow[t]{4}{*}{ A. } & . & M 0 & $3 \mathrm{~h}$ & $6 \mathrm{~h}$ & $9 \mathrm{~h}$ & $24 \mathrm{~h} 48 \mathrm{~h}$ & \multirow{4}{*}{ C $\begin{array}{c}\text { bp } \\
200 \\
200\end{array}$} & M 0 & $3 \mathrm{~h}$ & $6 \mathrm{~h}$ & $9 \mathrm{~h}$ & $48 \mathrm{~h}$ & \multirow{4}{*}{ Ubiquitin } \\
\hline & C $300=$ & - & - & - & - & -- & & - & - & - & - & - & \\
\hline & & $\mathrm{H}_{2} \mathrm{O}_{2}$ & - & - & - & -- & & $\mathrm{H}_{2} \mathrm{O}_{2}$ & - & - & - & - & \\
\hline & & SA & $x^{2}$ & & - & 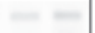 & & SA & - & - & - & - & \\
\hline
\end{tabular}
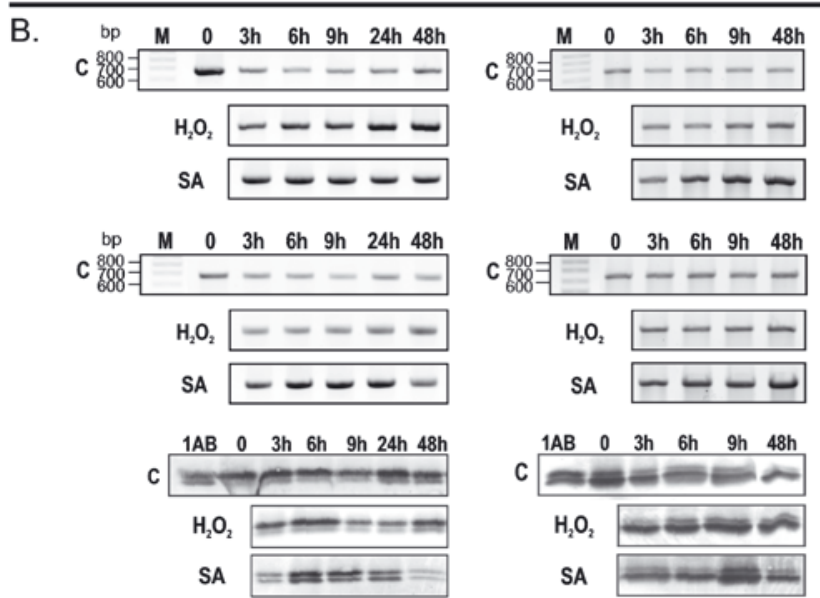

LIpr-10.1a

SA $\quad--\cdots$

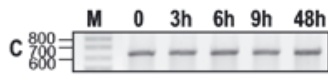

$\mathrm{H}_{2} \mathrm{O}_{2}---$

SA ----

$1 \mathrm{AB} \quad 0 \quad 3 \mathrm{~h} \quad 6 \mathrm{~h} \quad 9 \mathrm{~h} \quad 48 \mathrm{~h}$

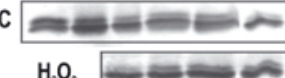

$\mathrm{H}_{2} \mathrm{O}_{2}$

SA

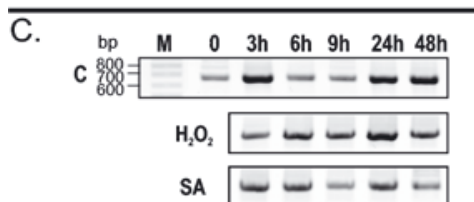

SA $-\infty-\infty$

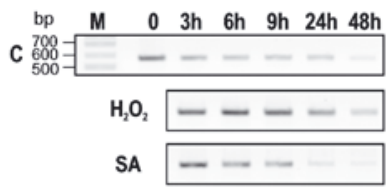

C $500-$

$\begin{array}{llllll}M & 0 & 3 \mathrm{~h} & 6 \mathrm{~h} & 9 \mathrm{~h} & 48 \mathrm{~h}\end{array}$

c $888= \pm---\cdots$

$\mathrm{H}_{2} \mathrm{O}_{2}=-$

SA $-=-$

$\begin{array}{llllll}M & 0 & 3 \mathrm{~h} & 6 \mathrm{~h} & 9 \mathrm{~h} & 48 \mathrm{~h}\end{array}$

${ }_{500}^{600}=-----$ $\mathrm{H}_{2} \mathrm{O}_{2}=-$

$\mathrm{SA} \quad---$

$\begin{array}{llllll}M & 0 & 3 \mathrm{~h} & 6 \mathrm{~h} & 9 \mathrm{~h} & 48 \mathrm{~h}\end{array}$ $c 880=---$

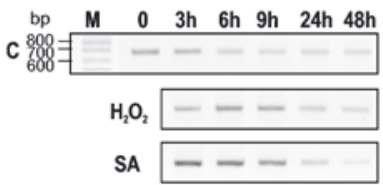

SA $--\ldots$

$2 A B \quad 0 \quad 3 h \quad 6 h \quad 9 h \quad 24 h \quad 48 h$

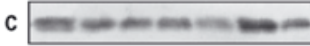

$\mathrm{H}_{2} \mathrm{O}_{2}$

SA

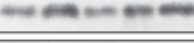

$-\ldots-\cdots$

$$
\mathrm{H}_{2} \mathrm{O}
$$

$---$

SA $-\infty--$

$\begin{array}{llllll}2 A B & 0 & 3 h & 6 h & 9 h & 48 h\end{array}$

C

$\mathrm{H}_{2} \mathrm{O}_{2}-2-m$

SA

$\frac{0}{\frac{0}{0}}$

Llpr-10 genes, generally increasing it in leaves. Especially both Llpr-10.1 subclass members and one gene representing subclass $L l p r-10.2$, Llpr-10.2a, gradually increased up to $48 \mathrm{~h}$ after treatment. Llpr-10.2b and Llpr-10.2e genes revealed a permanently enhanced expression level in leaves of plants watered with SA solution, comparing to control plant leaves. Interestingly, the same genes were clearly decreased in roots of the SA-treated plants. This antagonistic effect of salicylic acid was also visible at the LIPR10 protein level - evidently decreasing in roots 48 $\mathrm{h}$ after treatment and increasing in leaves $9 \mathrm{~h}$ after treatment. Both Western blots, with antibodies specific for LIPR-10.1 subclass as well as for LIPR-10.2 subclass, reflected this bias.

Figure 4. Expression of selected Llpr-10 genes in yellow lupine plants in response to elicitors: hydrogen peroxide $\left(\mathrm{H}_{2} \mathrm{O}_{2}\right)$ and salicylic acid (SA).

(A) Ubiquitin control; (B) subclass Llpr-10.1; (C) subclass Llpr-10.2. Total RNA template concentration and PCR cycle number were as follows: for ubiquitin $0.6 \mu \mathrm{g} / 35$ cycles; for $L l p r-10.2 a 0.6 \mu \mathrm{g} / 40$ cycles; for Llpr-10.1a, Llpr-10.1b, Llpr-10.2b and $L l p r-10.2 e-0.1 \mu \mathrm{g} / 30$ cycles. Western blot was performed separately with specific polyclonal antibodies against subclass L1PR-10.1 and LIPR10.2.

\section{Llpr-10.2b gene silencing}

Another approach applied for a functional analysis of yellow lupine pr-10 genes was gene silencing (Fire et al., 1998; Tijsterman et al., 2002; Szweykowska-Kulińska et al., 2003; Meister \& Tuschl, 2004; Baulcombe, 2005). RNA interference (RNAi) was used to switch off the Llpr-10.2b gene expression in yellow lupine plants. As any effective method of the gene silencing in legumes was elaborated up to date, we decided to prepare three versions of silencing vector differing in the orientation of the target gene: sense $\left(2 \mathbf{b}_{\mathrm{SE}}\right)$, antisense $\left(2 \mathbf{b}_{\mathrm{AS}}\right)$ and a hair pin $\left(\mathbf{2 b}_{\mathrm{HP}}\right.$, Fig. 5A). Plant leaves (infiltrated ones as well as those located above and below the 


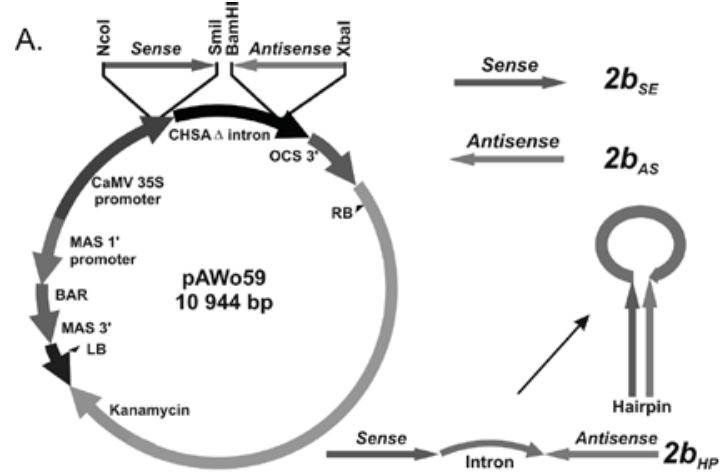

B.
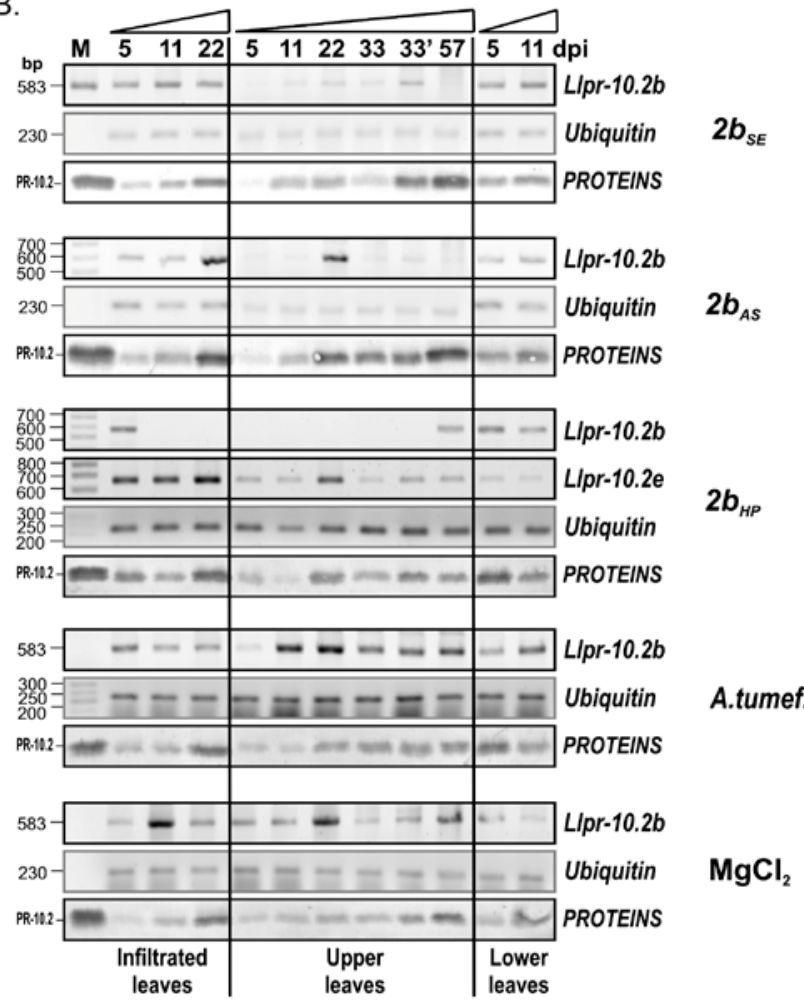

C.

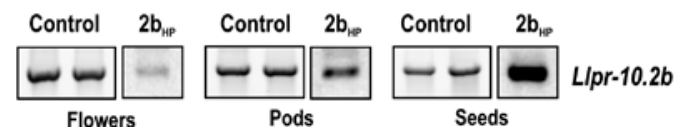

infiltration site) were separately collected 5, 11, 22, 33 and 57 days post infiltration (dpi). Target gene expression was analysed using semi-quantitative RTPCR method, supplemented by Western blot analysis with anti-LIPR-10.2B polyclonal antibodies as described earlier (Handschuh et al., 2004). RT-PCR with starters specific for lupine ubiquitin gene was applied as a control.

The sense construct $\left(\mathbf{2} \mathbf{b}_{\mathrm{SE}}\right)$ very slightly suppressed expression of the Llpr-10.2b gene in young leaves above the infliltration sites (Fig. 5B). Better results were obtained with the antisense construct $\left(2 \mathbf{b}_{\mathrm{AS}}\right)$ - for all upper leaves the level of Llpr-10.2b expression was clearly decreased, except for leaves collected 22 days after infiltration. Here, the Llpr$10.2 b$ gene was even overexpressed, comparing to the other samples and the ubiquitin control, which
Figure 5. Llpr-10.2b gene silencing in yellow lupine.

(A) Structure of the gene silencing vector and three Llpr-10.2b gene silencing constructs: sense $\left(2 \mathbf{b}_{\mathrm{SE}}\right)$, antisense $\left(2 \mathbf{b}_{\mathrm{AS}}\right)$ and hairpin $\left(2 \mathbf{b}_{\mathrm{HP}}\right)$. (B) Gene and protein expression pattern in yellow lupine leaves infiltrated with $A$. tumefaciens transformed with prepared silencing vectors. (C) Flowers, pods and seeds of plants used in silencing assay. As a control, plants infiltrated with wild type Agrobacterium or with $10 \mathrm{mM} \mathrm{MgCl}_{2}$ were applied. The effect of gene silencing was followed using RT-PCR with primers specific to Llpr-10.2b gene. For comparison ubiquitin expression level was monitored as a constitutively expressed gene. In the case of effective silencing of the Llpr-10.2b gene (hairpin construct; $\mathbf{2} \mathbf{b}_{\mathrm{HP}}$ ) RT-PCR was also performed with primers specific for homologous gene Llpr-10.2e. PCR and Western parameters were as described in Fig. 3. dpi - days post infiltration; 33 and $33^{\prime}$ - younger and older leaves from the same plants $33 \mathrm{dpi}$, respectively.

was observed in all infiltrated leaves. Only the hairpin construct $\left(\mathbf{2} \mathbf{b}_{\mathrm{HP}}\right)$ completely silenced the Llpr$10.2 b$ gene in leaves (Fig. 5B). Here, the RT-PCR product specific for the Llpr-10.2b gene was detected in infiltrated leaves only 5 days after infiltration whereas the upper leaves were free from $\mathrm{Llpr}-10.2 \mathrm{~b}$ gene transcript untill the 57th day after infiltration. Eleven days after infiltration Llpr-10.2b mRNA was detected only in leaves below the infiltration sites.

Surprisingly, the suppression events were not confirmed by the results of Western blot analysis. In all cases, the PR-10.2 protein level represents an upward tendency correlated with the age of the plants (Fig. 5B). This bias is, however, less visible in plants infiltrated with the hairpin construct.

In the control plants infiltrated with wild type Agrobacterium or with infiltration buffer only, tran- 
siently increased Llpr-10.2 expression was noticed 11 or/and 22 days after induction. No phenotype differences were observed between any groups of plants used for this experiment.

In order to confirm the specificity of silencing, RT-PCR with primers specific for the Llpr-10.2e gene, a close homologue of Llpr-10.2b, was performed. As shown in Fig. 5B the Llpr-10.2e gene remains expressed in the plants with silenced Llpr-10.2b gene, despite the high level of identity of both genes (90.7\%; Table 2). Nonetheless, the Llpr-10.2e expression seems to be slightly suppressed in the leaves above and below the infiltration site, comparing to infiltrated leaves.

\section{DISCUSSION}

In earlier reports we showed that yellow lupine $p r-10$ genes form a multigene family and despite a high protein sequence identity, they are differentially expressed in plant tissues (Sikorski et al., 1999; 2000; Handschuh et al., 2004). LlPR-10.1B, member of subclass LIPR-10.1, was constitutively expressed in the whole plant whereas its homologue, LIPR-10.1A, only in root and stem, being induced in leaves by pathogenic bacteria Pseudomonas syringae (Sikorski, unpuplished). Expression of the LlPR-10.2 subclass members was detected in all yellow lupine organs, but at different levels. Preliminary results showed that one of the Llpr-10.2 genes (Llpr-10.2a) was induced in leaves by salicylic acid (Handschuh et al., 2004). It was proved that all yellow lupine $p r-$ 10 genes are suppressed in nodulated roots (Sikorski et al., 2000).

The two new $p r-10.2$ genes presented here were identified in a yellow lupine genomic library. Their general structure is very similar to that of the previously discovered LlYpr-10.1 genes. Also the gene expression level of the new Llpr-10.2 subclass members resembles that of the Llpr-10.1 subclass, which can be concluded from the fact that identical RT-PCR parameters could be applied in order to detect the transcripts corresponding to the Llpr10.1a, Llpr-10.1b, Llpr-10.2b and Llpr-10.2e genes (Fig. $4 \mathrm{~B}$ and $\mathrm{C}$ ). The only exception is the Llpr-10.2a gene that is detectable by RT-PCR only when six times more of total RNA template is used and ten more PCR cycles follow reverse transcription. The expression of this gene, as it was expected, was increased in leaves of yellow lupine plants treated with salicylic acid (Fig. 4C). However, elevated levels of expression in leaves in response to salicylate were also observed for the other Llpr-10 genes studied. It corresponds with the fact that SA-response elements, such as TCA-like sequences described in tobacco, are present in all known yellow lupine pr-10 gene pro- moters, including the two presented in this report. pr-10 genes from other plant species also respond to salicylate and hydrogen peroxide, however, the kinetics of response often differs (Jwa et al., 2001; Rakwal et al., 2001). The antagonistic effect of SA on Llpr-10.2 gene expression in yellow lupine roots and leaves suggests that complex, organ-dependent regulation pathways are stimulated in plants by this elicitor. Endogenous SA, a key mediator of systemic acquired resistance (SAR), increases in plant tissues following pathogen infection and stimulates the expression of many genes engaged in defense response (Kunkel \& Brooks, 2002; Shah, 2003). Exogenously applied salicylate generates a similar effect. Salicylate-induced enhanced expression of Llpr-10 genes in yellow lupine leaves supports the hypothesis relating PR-10 proteins to pathogenesis.

Apart from the SA-response elements other regulatory motifs implicated in plant defense mechanisms were identified in the two Llpr-10.2 gene promoters studied. The most abundant are different variants of Dof motifs, recognized by plant-specific transcription factors regulating expression of a variety of signal-responsive genes, including those responsive to pathogens (Yanagisawa \& Schmidt, 1999; Yanagisawa, 2002). A single AC-rich H-box, present in defense-related genes, was found in both LlYpr10.2 promoters. Additionally, in the $L l Y$ pr-10.2f promoter another element, W-box, occurs in two copies. Vast families of plant transcription factors that bind to the W-boxes, WRKY proteins, regulate many pathogensis- and senescence-related genes (Eulgem et al., 1999; 2000; Turck et al., 2004). W-box presence in LlYpr-10.2f promoter seems to be one of the key arguments supporting this gene's classification as pathogensis-related. Although functional W-boxes are often gathered in clusters and act synergistically, even a single W-box is sufficient for WRKY-dependent regulation of transcription (Turck et al., 2004). In LlYpr-10.2f two W-boxes are separated from each other, so they rather act as two single, independent elements. The lack of a W-box in the LlYpr-10.2b promoter is a significant feature that distinguishes the two homologous gene promoters presented in this report.

It must be stressed here that some other important defense-related elements are absent in the studied LlYpr-10.2b and LlYpr-10.2f gene promoters. These motifs include G-box (CCACGTGG), responsible for reaction to biotic stress, GCC-box (AGCCGCC), ERE (ethylene-responsive element) and PR-box (GGCGGC), specific for some promoters of genes implicated in systemic acquired resistance (Singh et al., 2002). In fact, in wounded leaves we observed an elevated level of the studied Llpr10.2 gene transcripts (Fig. 3B). However, our results revealed that the same reason (wounding) caused 
the increase of Llpr-10.2 genes expression observed after pathogen infiltration, not the infection per se. That agrees with our preliminary Northern blot results (Sikorski et al., 2000) showing high level of transcripts belonging to the Llpr-10.2 subclass $1 \mathrm{~h}$ after Pseudomonas syringae infection, in contrast to the later response of Llpr-10.1a, a pathogen-inducible member of subclass Llpr-10.1. The kinetics of the response of $L l p r-10.2$ genes also suggested reaction to mechanical stress rather than to pathogen infection. It is possible that despite the high homology within the $p r-10$ gene family particular homologues can play slightly different roles or be recruited after different kinds of stress and pathogen.

Besides the pathogensis-related aspect discussed above, it must be underlined that PR-10 proteins are postulated to participate in general plant developmental program (Pozueta-Romero et al., 1995; Vanek-Krebitz et al., 1995; Balsamo et al., 1995; Swoboda et al., 1996; Huang et al., 1997; Strömvik et al., 1999; Sikorski et al., 1999; Liu \& Ekramoddoullah, 2003; Beuning et al., 2004; Finkler et al., 2005). Both pr-10 gene promoters studied here contain hormoneresponse element (HRE) specific for genes regulated by gibberellins (TAACAA). Additionally, the majority of transcription factors that potentially bind to the sequences identified in the Llpr-10.2 gene promoters and mediate stress-response can also participate in developmental processes, revealing time- and organdependent activities and mediating tissue-specific expression. For instance, Dof proteins mediate not only defense but also light and phytohormone response, seed development and germination (Yanagisawa \& Schmidt, 1999; Yanagisawa, 2002). The expression analysis results presented here evidently prove that $p r-10.2$ genes are generally sensitive to any kind of environmental or developmental changes. The elicitor-independent increase of PR-10 protein amount in yellow lupine leaves with ageing (Figs. 3 and 5) reaches the highest level in senescent leaves, which is typical for many $p r-10$ proteins (Crowell et al., 1992; Puhringer et al., 2000). Arabidopsis genomic studies of 402 transcription factors revealed that the expression of stress-related genes is often correlated with senescence (Yanagisawa, 2002).

The analysis of the two $p r-10.2$ promoter sequences revealed many common sites as well as substantial variations that can determine their expression pattern in plants. Within the LlYpr-10.2b gene promoter also an auxin-response element (auxRE) was identified. This motif consists of two 6-nucleotide parts (TGTCTC and AATAAG) separated by several nucleotides (here $12 \mathrm{nt}$ ). Only one of these parts is present in the LlYpr-10.2f gene promoter, which is probably not sufficient for interaction with auxin-dependent transcription factors. Instead, the LlYpr-10.2f promoter has one glucocorticoid-response element (GRE), absent in the LlYpr-10.2b gene promoter. These differences can determine the diverse mode of expression of the yellow lupine pr-10.2 genes, as a consequence of regulation by different plant hormones. Although no substantial differences in expression were observed between the Llpr-10.2b and Llpr-10.2f genes in yellow lupine or in transgenic tobacco during plant development, a distinct expression pattern after stimulation by factors not assayed in this study cannot be excluded. The influence of plant hormones on expression of Llpr-10.2 genes needs further experimental verification. The impact of jasmonate, ethylene, abscisic acid, kinetin and zeatin is under investigation.

Llpr-10.2b gene silencing, although successful, did not help to explain the function of PR-10 proteins, either. We succeeded in silencing Llpr-10.2b gene in leaves of mature yellow lupine plants using Agrobacterium tumefaciens as a carrier. The Llpr-10.2b gene silencing was effective only when the hairpin construct was introduced into leaves, in compliance with literature data reporting better efficiency of gene silencing triggered by double-stranded RNA (Chen et al., 2002; Colditz et al., 2007). However, it was difficult to conclude the function of $p r-10$ genes as the Llpr-10.2b gene absence did not cause any visible symptoms. The most probable explanation bases on the fact that the studied gene belongs to a multigene family. Presumably we observed a situation when one absent gene was substituted for another family member. The fact that silencing of the target gene was not accompanied by efficient silencing of its close homologue, Llpr-10.2e, sharing 90\% identity within the coding sequence and representing a similar constitutive expression pattern, seems to support this hypothesis. Also Western blot analysis shows an invariable protein accumulation level, despite Llpr$10.2 b$ transcript absence. Western analysis reported here represents the whole LIPR-10.2 subclass expression, comprising at least six different proteins. Therefore, subtle differences in the levels of individual proteins cannot be noticed. Additionally, protein accumulation does not always reflect the fluctuations observed at the transcript level. Apparently, silencing of the whole $p r-10$ family would be more informative. Alternatively, another plant model could be used, with fewer $p r-10$ family members than in yellow lupine. It is also possible that $p r-10$ gene silencing is not harmful to a mature plant and that it should be performed at an early stage of plant development. Moreover, gene silencing conjugated with elicitor-induction experiments can be helpful. Such an approach was recently successfully applied by Colditz et al. (2006) who silenced PR10-1 protein in Medicago truncatula. Despite the knockdown Medicago transgenic line revealing almost complete silencing of five additional homologues of the target 
gene, the authors did not observe any morphological differences in the studied root cultures. Changes appeared only when the silenced line was submitted to infection with the oomycete pathogen Aphanomyces euteiches, the major parasite of legumes. Here, the lack of PR10-like proteins was accompanied by overexpression of other, non-homologous, PR defense proteins and in consequence the suppression of pathogen infection development, contrary to the expected result. Undoubtedly, to confirm the contribution of the yellow lupine pr-10.2 genes presented here to the plant defense reactions, further functional analysis is necessary, including studies of gene expression response to other pathogens and stressrelated factors.

Summarizing, the presented results showed that yellow lupine $p r-10$ genes are precisely regulated and can be differentially expressed despite high sequence homology. They are implicated not only in plant defense mechanisms, but constitute a substantial part of plant developmental program. However, temporal silencing of one $p r-10$ family member is neutral to the mature yellow lupine plants while the other homologues are still present. The exact biological role of PR-10 proteins still needs to be determined.

\section{Acknowledgements}

The work was supported by grants from the State Committee for Scientific Research: No. PBZKBN-089/P06/2003 to M.F. and No. 3 P04A 03224 to M.S.

\section{REFERENCES}

Akiyama Y, Onizuka K, Noguchi T, Ando M (1998) Parallel Protein Information Analysis (PAPIA) System Running on a 64-Node PC Cluster. Genome Informatics 9: 131-140 (http: //www.rwcp.or.jp/papia/).

Bais HP, Vepachedu R, Lawrence CB, Stermitz FR, Vivanco JM (2003) Molecular and biochemical characterization of an enzyme responsible for the formation of hypericin in St. John's Wort (Hypericum perforatum L.). J Biol Chem 278: 32413-32422.

Balsamo RA, Wang JL, Eckard KJ, Wang C-S, Lord EM (1995) Immunogold localization of a developmentally regulated, tapetal-specific, $15 \mathrm{kDa}$ lily anther protein. Protoplasma 189: 17-25.

Bantignies B, Seguin J, Muzac I, Dedaldechamp F, Gulick P, Ibrahim R (2000) Direct evidence for ribonucleolytic activity of a PR-10-like protein from white lupin roots. Plant Mol Biol 42: 871-881.

Baulcombe D (2005) RNA silencing. Trends Biochem Sci 6: 290-293.

Beuning L, Bowen J, Persson H, Barraclough D, Bulley S, MacRae EA (2004) Characterisation of Mal d 1-related genes in Malus. Plant Mol Biol 55: 369-388.

Breda C, Sallaud Ch, El-Turk J, Buffard D, de Kozak I, Esnault R, Kondorosi A (1996) Defense reaction in Medicago sativa: a gene encoding a class $10 \mathrm{PR}$ protein is expressed in vascular bundles. Mol Plant Microbe Inter 8: 713-719.

Bufe A, Spangfort MD, Kahlert H, Schlaak M, Becker W-M (1996) The major birch pollen allergen, Bet v 1, shows ribonuclease activity. Planta 199: 413-415.

Chadha P, Das RH (2006) A pathogensis related protein, AhPR10 from peanut: an insight of its mode of antifungal activity. Planta 225: 213-222.

Chen W, Provart NJ, Glazebrook J, Katagiri F, Chang HS, Eulgem T, Mauch F, Luan S, Zou G, Whitham SA et al. (2002) Expression profile matrix of Arabidopsis transcription factor genes suggests their putative functions in response to environmental stresses. Plant Cell 14: 559-574.

Colditz F, Niehaus K, Krajinski F (2007) Silencing of PR10-like proteins in Medicago truncatula results in an antagonistic induction of other PR proteins and in an increased tolerance upon infection with the oomycete Aphanomyces euteiches. Planta 226: 57-71.

Crowell DN, John ME, Russel D, Amasino M (1992) Characterization of a stress-induced, developmentally regulated gene family from soybean. Plant Mol Biol 18: $459-466$.

Eulgem T, Rushton PJ, Robatzek S, Somssich IE (2000) The WRKY superfamily of plant transcription factors. Trends Plant Sci 5: 199-205.

Eulgem T, Rushton PJ, Schmelzer E, Hahlbrock K, Somssich IE (1999) Early nuclear events in plant defense signaling: rapid gene activation by WRKY transcription factors. EMBO J 18: 4689-4699.

Finkler C, Giacomet C, Muschner VC, Salzano FM, Freitas LB (2005) Molecular investigations of pathogensisrelated Bet v1 homologues in Passiflora (Passifloraceae). Genetica 124: 117-125.

Fire A, Xu S, Montgomery MK, Kostas SA, Driver SE, Mello CC (1998) Potent and specific genetic interference by double-stranded RNA in Caenorhabditis elegans. Nature 391: 806-811.

Gamas P, de Billy F, Truchet G (1998) Symbiosis-specific expression of two Medicago truncatula nodulin genes, MtN1 and MtN13, encoding products homologous to plant defense proteins. MPMI 5: 393-403.

Handschuh L, Femiak I, Kasperska A, Sikorski MM (2003) Pathogensis-Related Proteins of Subclass PR-10.2 in Yellow Lupine - Comprehensive Analysis, Proceedings of the XIIth International Congress on "Genes, Gene Families and Isozymes", Berlin, pp157-160.

Heinemeyer T, Wingender E, Reuter I, Hermjakob H, Kel $\mathrm{AE}$, Kel OV, Ignatieva EV, Ananko EA, Podkolodnaya OA, Kolpakov FA, Podkolodny NL, Kolchanov NA (1998) Databases on Transcriptional Regulation: TRANSFAC, TRRD, and COMPEL. Nucleic Acids Res. 26: 364-370 (http: //www.cbrc.jp/research/db/TFSEARCH.html).

Hoffmann-Sommergruber K, Vanek-Krebitz M, Radauer Ch, Wen J, Ferreira F, Scheiner O, Breitender H (1997) Genomic characterization of members of the Bet $v 1$ family: genes coding for allergens and pathogensis-related proteins share intron positions. Gene 197: 91-100.

Huang J-C, Chang F-C, Wang C-S (1997) Characterization of a lily tapetal transcript that shares sequence similarity with a class of intracellular pathogensis-related (IPR) proteins. Plant Mol Biol 34: 681-686.

Jefferson RA, Kavanagh TA, Bevan MW (1987) GUS fusions: $\beta$-glucuronidase as a sensitive and versatile gene fusion marker in higher plants. EMBO J 6: 3901-3907.

Jwa N-S, Agrawal GK, Rakwal R, Park C-H, Agrawal VP (2001) Molecular cloning and characterization of a novel jasmonate inducible pathogenesis-related class 10 
protein gene, JIOsPR10, from rice (Oryza sativa L.) seedling leaves. Biochem Biophys Res Commun 286: 973-983.

Kunkel BN, Brooks DM (2002) Cross talk between signaling pathways in pathogen defense. Curr Opin Plant Biol 5: 325-331.

Liscombe DK, MacLeod BP, Loukanina N, Nandi OI, Facchini PJ (2005) Evidence for the monophyletic evolution of benzylisoquinoline alkaloid biosynthesis in angiosperms. Phytochemistry 66: 1374-1393.

Liu J-J, Ekramoddoullah AK (2003) Root-specific expression of a western white pine PR10 gene is mediated by different promoter regions in transgenic tobacco. Plant Mol Biol 52: 103-120.

Liu JJ, Ekramoddoullah AK (2004) Characterization, expression and evolution of two novel subfamilies of Pinus monticola cDNAs encoding pathogensis-related (PR)-10 proteins. Tree Physiol 24: 1377-1385.

McGee JD, Hamer JE, Hodges TK (2001) Characterization of a PR-10 pathogensis-related gene family induced in rice during infection with Magnaporthe grisea. Mol Plant Microbe Inter 14: 877-886.

Meister G, Tuschl T (2004) Mechanisms of gene silencing by double-stranded RNA. Nature 431: 343-349.

Mishra NS, Tuteja R, Tuteja N (2006) Signaling through MAP kinase networks in plants. Arch Biochem Biophys 452: 55-68.

Moiseyev GP, Beintema JJ, Fedoreyeva LI, Yakovlev GI (1994) High sequence similarity between a ribonuclease from ginseng calluses and fungus-elicited proteins from parsley indicates that intracellular pathogensis-related proteins are ribonucleases. Planta 193: 470-472.

Moiseyev GP, Fedoreyeva LI, Zhuravlev YN, Yasnetskaya E, Jekel PA, Beintema JJ (1997) Primary structures of two ribonucleases from ginseng calluses. New members of the PR-10 family of intracellular pathogensis-related plant proteins. FEBS Lett 407: 207-210.

Park C-J, Kim K-J, Shin R, Park JM, Shin J-C, Paek K-H (2004) Pathogensis-related protein 10 isolated from hot pepper functions as a ribonuclease in an antiviral pathway. Plant J 37: 186-198.

Pasternak O, Bujacz GD, Fujimoto Y, Hashimoto Y, Jelen F, Otlewski J, Sikorski MM, Jaskolski M (2006) Crystal structure of Vigna radiata cytokinin-specific binding protein in complex with zeatin Plant Cell 18: 2622-2634.

Pinto MP, Ricardo CPP (1995) Lupinus albus L. pathogensis-related proteins that show similarity to PR-10 proteins. Plant Physiol 109: 1345-1351.

Pozueta-Romero J, Klein M, Houlne G, Schantz M-L, Meyer B, Schantz R (1995) Characterization of a family of genes encoding a fruit-specific wound-stimulated protein of bell pepper (Capsicum annuum): identification of a new family of transposable elements. Plant Mol Biol 28: 1011-1025.

Pühringer H, Moll D, Hoffmann-Sommergruber K, Watillon B, Katinger H, Laimer da Camara Machado M (2000) The promoter of an apple Ypr10 gene, encoding the major allergen Mal d 1, is stress- and pathogen-inducible. Plant Sci 152: 35-50.

Rakwal R, Agrawal GK, Yonekura M (2001) Light-dependent induction of OsPR10 in rice (Oryza sativa L.) seedlings by the global stress signaling molecule jasmonic acid and protein phosphatase $2 \mathrm{~A}$ inhibitors. Plant Sci 161: 469-479.

Schenk MF, Gilissen LJ, Esselink GD, Smulders MJ (2006) Seven different genes encode a diverse mixture of isoforms of Betv 1, the major birch pollen allergen. BMC Genomics 7: 168.

Schug J (2003) Using TESS to predict transcription factor binding sites in dna sequence. In Current Protocols in
Bioinformatics, Baxevanis, Andreas D, eds, Wiley J and Sons (publisher) (http: //www.cbil.upenn.edu/cgi-bin/ tess/tess)

Shah J (2003) The salicylic acid loop in plant defense. Curr Opin Plant Biol 6: 365-371.

Sikorski MM (1997) Expression of Lupinus luteus cDNA coding for PR10 protein in Escherichia coli: Purification of the recombinant protein for structural and functional studies. Acta Biochim Polon 44: 565-578.

Sikorski MM, Szlagowska AE, Legocki AB (1998) Structure of Lupinus luteus genes Ypr10.1a and Ypr10.1b encoding two homologues of pathogenesis-related proteins of PR10 class. Plant Physiol 116: 1192-1195.

Sikorski MM, Biesiadka J, Kasperska AE, Kopcińska J, Łotocka B, Golinowski W, Legocki AB (1999) Expression of genes encoding PR10 class pathogensis-related proteins is inhibited in yellow lupine root nodules. Plant Sci 149: 125-137.

Sikorski MM, Stępkowski T, Świderska A, Biesiadka J, Łotocka B, Kopcińska J, Golinowski W, Legocki AB (1999) Differential expression of symbiosis-related genes in yellow lupine. In Highlights of Nitrogen Fixation Research, pp 125-130. Plenum Publishing Corporation, New York.

Sikorski MM, Handschuh L, Biesiadka J, Legocki AB (2000) Two subclasses of yellow lupine PR10 proteins and their possible function during the symbiosis development. Curr Plant Sci Biotech Agriculture 38: 319-322.

Silverstein KA, Graham MA, VandenBosch KA (2006) Novel paralogous gene families with potential function in legume nodule sand seeds. Curr Opin Plant Biol 2: 142-146.

Singh KB, Foley RC, Onate-Sanchez L (2002) Transcription factors in plant defense and stress response. Curr Opin Plant Biol 5: 430-436.

Somssich IE, Schmelzer E, Bollmann J, Hahlbrock K (1986) Rapid activation by fungal elicitor of genes encoding "pathogensis-related" proteins in cultured parsley cells. Proc Natl Acad Sci USA 83: 2427-2430.

Somssich IE, Schmelzer E, Kawalleck P, Hahlbrock K (1988) Gene structure and in situ transcript localization of pathogensis-related protein 1 in parsley. Mol Gen Genet 213: 93-98.

Strömvik MW, Sundararaman VP, Vodkin LO (1999) A novel promoter from soybean that is active in a complex developmental pattern with and without its proximal 650 base pairs. Plant Mol Biol 41: 217-231.

Swoboda I, Hoffman-Sommergruber K, O'Riordain G, Scheiner O, Heberle-Bors E, Vicente O (1996) Bet v 1 proteins, the major birch pollen allergens and members of a family of conserved pathogensis-related proteins, show ribonuclease activity in vitro. Physiol Plantar 96: 433-438.

Szweykowska-Kulińska Z, Jarmolowski A, Figlerowicz M (2003) RNA interference and its role in the regulation of eucaryotic gene expression. Acta Biochim Polon 50: 217-229.

Ślesak I, Libik M, Karpinska B, Karpinski S, Miszalski Z (2007) The role of hydrogen peroxide in regulation of plant metabolism and cellular signaling in response to environmental stresses. Acta Biochim Polon 54: 39-50.

Tijsterman M, Ketting RF, Plasterk RHA (2002) The genetics of RNA silencing. Annu Rev Genet 36: 489-519.

Trinh H, Barker D, Ratet P (2001) Regeneration and transformation methods in the Manuals of The EMBO Practical course on the New Plant Model System Medicago truncatula, Module 2, organized by Pascal Ratet.

Turck F, Zhou A, Somssich IE (2004) Stimulus-dependent, promoter-specific binding of transcription factor 
WRKY1 to its native promoter and the defense-related gene PCPR1-1 in parsley. Plant Cell 16: 2573-2585.

van Loon LC, van Strien EA (1999) The families of pathogensis-related proteins, their activities, and comparative analysis of PR-1 type proteins. Physiol Mol Plant Pathol 55: 85-97.

Vanek-Krebitz M, Hoffmann-Sommergruber K, Laimer da Câmara Machado M, Susani M, Ebner C, Kraft D, Scheiner O, Breitender H (1995) Cloing and sequencing of Mal d 1, the major allergen from apple (Malus domestica) and its immunological relationship to Bet $\mathrm{v}$ 1, the major birch pollen allergen. Biochem Biophys Res Commun 214: 538-551.

Walter MH, Liu J-W, Wünn J, Hess D (1996) Bean ribonuclease-like pathogensis-related protein genes (Ypr10) display complex patterns of developmental, dark-induced and exogenous-stimulus-dependent expression. Eur J Biochem 239: 281-293.
Wang C-S, Huang J-C, Hu J-H (1999) Characterization of two subclasses of PR-10 transcripts in lily anthers and induction of their genes through separate signal transduction pathways. Plant Mol Biol 40: 807-814.

Wu F, Yan M, Li Y, Chang S, Song X, Zhou Z, Gong W (2003) cDNA cloning, expression, and mutagenesis of a PR-10 protein SPE-16 from the seeds of Pachyrrhizus erosus. Biochem Biophys Res Commun 312: 761-766.

Yanagisawa S (2002) The Dof family of plant transcription factors. Trends Plant Sci 7: 555-560.

Yanagisawa S, Schmidt RJ (1999) Diversity and similarity among recognition sequences of Dof transcription factors. Plant J 17: 209-214.

Zhou X-J, Lu S, Xu Y-H, Wang J-W, Chen X-Y (2002) A cotton cDNA (GaPR-10) encoding a pathogensis-related 10 protein with in vitro ribonuclease activity. Plant Sci 162: 629-636. 